International Journal of Modern Physics B,

Vol. 19, No. 21 (2005) 3413

(c) World Scientific Publishing Company

\title{
ERRATA
}

\section{MICROCRYSTALLINE SILICON FILMS PREPARED BY VERY HIGH FREQUENCY PLASMA ENHANCED CHEMICAL VAPOR DEPOSITION AT LOW TEMPERATURE}

\author{
[International Journal of Modern Physics B, Vol. 19, No. 18 (2005) 3013-3020] \\ ZHIMENG WU*, QINGSONG LEI and JIANPING XI \\ Research Institute of Micro/Nano Science and Technology, \\ Shanghai Jiao Tong University, Shanghai 200030, P. R. China \\ *zhimangwu@hotmail.com \\ ZHAO YING and XINHUA GENG \\ Institute of Optoelectronics, Nankai University, Tianjin 300071, P. R. China
}

On page 3014, the first sentence of Sec. 3.1 should read as:

Figure 1 shows the deposition rate and photosensitivity of silicon films as a functin of the silane concentration at the power density of $0.4 \mathrm{~W} / \mathrm{cm}^{2}$.

On page 3017, Fig 5 should be shown as follows:

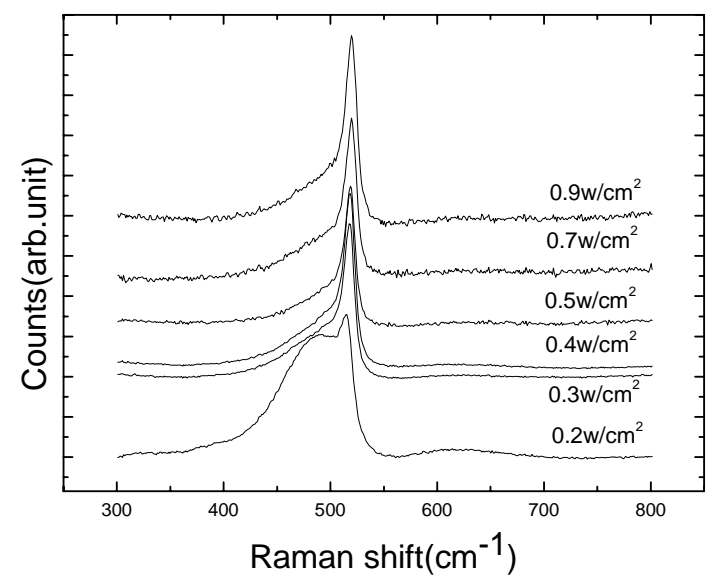

Fig. 5. Raman spectra for films deposited at different power density.

The authors apologize for the errors made. 